\title{
Comunicação
}

\section{Aclimatização de mudas micropropagadas de Bastão do Imperador em diferentes volumes de recipientes ${ }^{1}$}

\author{
Elisangela Maria dos Santos ${ }^{2}$, Benito Moreira de Azevedo ${ }^{3}$, Albanise Barbosa Marinho ${ }^{4}$, \\ Ana Cristina Portugal Pinto de Carvalho ${ }^{5}$, Kleiton Rocha Saraiva ${ }^{6}$
}

\section{RESUMO}

É crescente o mercado de flores tropicais no Brasil. No nordeste, por causa do clima, torna-se difícil a aclimatização dessas plantas. Portanto, este trabalho tem por objetivo determinar o recipiente mais adequado para aclimatizar mudas micropropagadas de bastão do imperador cv. Porcelana, em ambiente protegido. O experimento foi realizado em estufa e as mudas utilizadas foram obtidas por micropropagação. $\mathrm{O}$ delineamento experimental utilizado foi de blocos ao acaso, com quatro tratamentos (volumes) e cinco repetições. Os volumes dos recipientes testados foram: $\mathrm{V}_{1}-50 \mathrm{~cm}^{3}$ (Copo pequeno - CP) $; \mathrm{V}_{2}-150 \mathrm{~cm}^{3}$ (Tubete pequeno - TP) $; \mathrm{V}_{3}-300 \mathrm{~cm}^{3}$ (Tubete grande - TG) $\mathrm{V}_{4}-450 \mathrm{~cm}^{3}$ (Vaso pequeno - VP). Foram coletados dados correspondentes ao número de folhas (NF), altura da muda (AM), diâmetro do pseudocaule (DP), massa fresca da parte aérea (MFPA), massa fresca do sistema radicular (MFSR), massa seca da parte aérea (MSPA) e massa seca do sistema radicular (MSSR). Foi realizada a análise de variância e os resultados de natureza qualitativa foram submetidos ao teste de média. $O$ vaso de $450 \mathrm{~cm}^{3}$ é o recipiente mais adequado para aclimatização de bastão do imperador, pois proporcionou melhor desenvolvimento das mudas.

Palavras-chave: Etlingera elatior, cultivo protegido, floricultura.

\section{ABSTRACT}

\section{Acclimatization of micropropagated seedlings of Torch Lily in containers of different capacities}

The Brazilian market of tropical flowers is in a rapid growth stage. The climate of the Brazilian northeastern region, however, tends to hamper plant acclimatization. Considering this, our study aims at determining the most appropriate container (concerning to capacity) to acclimatize micropropagated Torch Lily (cultivar Porcelana) in a greenhouse. The experimental design was randomized blocks with four treatments (container capacities) and five replications. The tested container capacities were: $\mathrm{V} 1=50 \mathrm{~cm}^{3}$ (small glass $-\mathrm{CP}$ ); $\mathrm{V} 2=150 \mathrm{~cm}^{3}$ (small plastic tube $\left.-\mathrm{TP}\right) ; \mathrm{V} 3=300 \mathrm{~cm}^{3}$ (large plastic tube - TG); V4 $=450 \mathrm{~cm}^{3}$ (small vase - VP). The characteristics evaluated were: the number of leaves (NF), seedling height (AM), stem diameter (DP), fresh shoot weight (MFPA), fresh root weight (MFSR), dry shoot weight (MSPA) and dry root weight (MSSR). Data were examined by analysis of variance and the Tukey test. The results point to the $450 \mathrm{~cm}^{3}$ container as the best suited for Torch Lily acclimatization, since it provided the best seedling growth.

Key words: Etlingera elatior, greenhouse cultivation, floriculture.

\footnotetext{
Recebido para publicação em 12/01/2012 e aprovado em 30/11/2012.

${ }^{1}$ Trabalho extraído de Dissertação de mestrado.

${ }^{2}$ Engenheira-Agrônoma, Mestre. Universidade Federal do Ceará, Campus do Pici, Bl. 804, s/n, Planalto do Pici, 60455-760, Fortaleza, Ceará, Brasil. emsufc @ gmail.com

${ }^{3}$ Engenheiro-Agrônomo, Doutor. Universidade Federal do Ceará, Campus do Pici, Bl. 804, s/n, Planalto do Pici, 60455-760, Fortaleza, Ceará, Brasil. benito@ ufc.br

${ }^{4}$ Engenheira-Agrônoma, Doutora. Universidade da Integração Internacional da Lusofonia Afro-Brasileira, Rua Doutora Sara Mesquita, 2270, Planalto do Pici,

60511-110, Fortaleza, Ceará, Brasil. albanisebm@gmail.com

5Bióloga, Doutora. Embrapa - Agroindústria Tropical, Rua Doutora Sara Mesquita, 2270, Planalto do Pici, 60511-110, Fortaleza, Ceará, Brasil. cristina@ cnpat.embrapa.br

${ }^{6}$ Engenheiro-Agrônomo, Mestre. Universidade Federal do Ceará, Campus do Pici, Bl. 804, s/n, Planalto do Pici, 60455-760, Fortaleza, Ceará, Brasil. kleitonagro@ bol.com.br (autor para correspondência)
}

Rev. Ceres, Viçosa, v. 60, n.1, p. 134-137, jan/fev, 2013 


\section{INTRODUÇÃO}

O mercado de flores tropicais no nordeste brasileiro está em pleno crescimento, principalmente, graças a fatores favoráveis como, clima, disponibilidade de solo, água, energia e mão de obra. Em decorrência desses fatores, a região tem potencial para produzir flores tropicais com maior qualidade, a custo mais baixo e, consequentemente, a preços mais competitivos (Loges et al., 2005).

Entre as Zingiberáceas, que são espécies tropicais ornamentais, destaca-se o bastão do imperador (Etlingera elatior), planta originária da Malásia, que vem sendo cultivada há muitos anos na região, com grandes potencialidades, principalmente como flor de corte. Suas mudas normalmente são obtidas por divisão de touceiras, ou por sementes; esta prática pode, porém, acarretar diversos problemas durante o cultivo (Bezerra \& Loges, 2005).

A micropropagação de plantas ornamentais oferece ao produtor mudas de elevada e padronizada qualidade, em quantidade suficiente para suprir, em curto espaço de tempo, a demanda crescente de um mercado cada vez mais exigente. (Bomfim, 2006).

A aclimatização é a etapa na qual a planta é transferida do laboratório (in vitro) para o ambiente de cultivo (ex vitro). É etapa crítica e representa, em muitos casos, o principal percalço na micropropagação de muitas espécies (Brainerd \& Fuchigami, 1981).

Vários fatores podem influenciar a aclimatização de plantas micropropagadas, dentre os quais pode-se destacar o volume do recipiente, de fundamental importância, na produção em larga escala, por envolver questões de maior aproveitamento de espaço físico dentro da casa de vegetação. Em vista disso, objetivou-se, neste trabalho, determinar o recipiente mais adequado para aclimatização de mudas micropropagadas de bastão do imperador cv. Porcelana, em ambiente protegido.

\section{MATERIAL E MÉTODOS}

O experimento foi conduzido em ambiente protegido, pertencente à Embrapa Agroindústria Tropical (CNPAT), no período de junho a agosto de 2009. A área está situada no município de Fortaleza, Ceará. O experimento foi conduzido em estufa, com área total de $156 \mathrm{~m}^{2}$. Toda a estrutura foi coberta por tela de sombreamento, para reduzir em $70 \%$ a luminosidade, e uma cobertura com plástico transparente, para proteção de intempéries climáticas. Em seu interior, foi instalado um túnel semicircular, revestido por plástico transparente, para proteger as plantas contra a influência de intempéries climáticas e possíveis pragas.

Foram utilizadas mudas micropropagadas de bastão do imperador (Etlingera elatior), cv Porcelana, obtidas de material in vitro, na seguinte sequência: lavagem das raízes, secagem em papel toalha, poda das raízes e plantio.
Antes do transplantio, os recipientes, contendo substratos, foram irrigados. Após o transplantio, além da irrigação, utilizou-se spray com água para aumentar a umidade relativa do ambiente. Também, quinzenalmente, as mudas receberam uma suplementação com fertilizante mineral foliar.

O delineamento experimental foi em blocos ao acaso, com quatro tratamentos (volumes) e cinco repetições. Os volumes dos recipientes testados foram: $\mathrm{V}_{1}-50 \mathrm{~cm}^{3}$ (Copo pequeno - $\mathrm{CP}$ ); $\mathrm{V}_{2}-150 \mathrm{~cm}^{3}$ (Tubete pequeno - TP) $\mathrm{V}_{3}-300$ $\mathrm{cm}^{3}$ (Tubete grande - TG); $\mathrm{V}_{4}-450 \mathrm{~cm}^{3}$ (Vaso pequeno - VP).

Os tubetes eram de material plástico, do tipo polietileno rígido, de coloração preta, formato cônico e afunilado e aberto na extremidade inferior; o copo pequeno, de plástico descartável, de coloração branca e, o vaso pequeno, de material polietileno rígido, de coloração preta, todos com perfurações para facilitar a drenagem. Esses recipientes foram preenchidos com substrato comercial e colocados em quatro bancadas, suspensas a $0,90 \mathrm{~m}$ do solo.

A irrigação foi iniciada logo após o transplantio, sendo realizada com base na evaporação diária do minitanque evaporímetro. A irrigação era realizada quando a evaporação de água, medida no minitanque, atingia valor maior ou igual $4 \mathrm{~mm}$. Esse valor foi atingido, em média, a cada dois dias. As irrigações foram efetuadas às $9 \mathrm{~h}$.

Após o transplantio, realizou-se a primeira coleta de dados dos seguintes parâmetros: número de folhas (NF), altura da muda (AM) e diâmetro do pseudocaule (DP), e posteriormente, aos 31 dias após o transplantio (DAT) e aos 50 DAT. O número de folhas foi contado em toda a planta. A altura da muda e o diâmetro do pseudocaule foram medidos com paquímetro digital.

Posteriormente, foram obtidas a massa fresca da parte aérea (MFPA), a massa fresca do sistema radicular (MFSR), a massa seca da parte aérea (MSPA) e a massa seca do sistema radicular (MSSR).

Utilizando-se o software SAEG 9.0 (SAEG, 2005), os dados foram submetidos à análise de variância, e, quando significativo, pelo teste $\mathrm{F}$, a $5 \%$ de probabilidade, foi realizado o teste de médias, por meio do teste de Tukey, a 5\% de probabilidade.

\section{RESULTADOS E DISCUSSÃO}

Verificou-se que o maior valor, observado em relação à altura das plantas, foi de $5,23 \mathrm{~cm}$, proporcionado pelo vaso pequeno, não diferindo, porém, das alturas das mudas aclimatizadas no tubete grande $(5,19 \mathrm{~cm})$ (Tabela 1). A menor altura foi verificada no copo pequeno $(2,66 \mathrm{~cm})$. Os diferentes volumes de recipientes não influenciaram no número de folhas, que apresentou valor médio de 2,63.

Em relação ao diâmetro do pseudocaule, verificou-se que os melhores resultados foram obtidos com o tubete grande $(0,41 \mathrm{~cm})$, vaso pequeno $(0,39 \mathrm{~cm})$ e tubete peque- 
no $(0,39 \mathrm{~cm})$, os quais não diferiram estatisticamente entre si, enquanto o resultado inferior foi obtido pelo copo pequeno $(0,35 \mathrm{~cm})$, sem diferir, porém, dos diâmetros dos pseudocaules das mudas cultivadas em tubete pequeno e vaso pequeno. Verificou-se, pelas análises aos 31 DAT, que o desenvolvimento da planta foi pior no recipiente de menor capacidade volumétrica.

Segundo Kämpf (2000), em comparação com o cultivo a campo, onde as plantas dispõem de volume ilimitado para o crescimento de suas raízes, no cultivo em recipientes o volume é reduzido, o que diminui a drenagem e a superfície de contato com a atmosfera, essencial para as trocas gasosas $\left(\mathrm{CO}_{2}\right.$ e $\left.\mathrm{O}_{2}\right)$. Também, a forma e o tamanho do recipiente influenciam na movimentação da água no volume de solo do recipiente.

Observou-se que a diferença de volumes dos recipientes influenciou, significativamente, quase todas as variáveis analisadas (Tabela 2), exceto a variável MSSR, que não apresentou diferença significativa.

Observa-se, na Tabela 2, que os maiores valores de AM, NF, DP, MFPA, MFSR e MSPA, foram obtidos com o

Tabela 1. Valores médios das variáveis: altura da muda (AM), número de folhas (NF) e diâmetro do pseudocaule (DP) das mudas de bastão do imperador em função do volume dos recipientes, aos 31 DAT

\begin{tabular}{llll}
\hline $\begin{array}{l}\text { Volumes dos } \\
\text { Recipientes }\left(\mathbf{c m}^{3}\right)\end{array}$ & $\begin{array}{c}\text { AM } \\
(\mathbf{c m})\end{array}$ & NF & $\begin{array}{c}\text { DP } \\
(\mathbf{c m})\end{array}$ \\
\hline 50 & $2,66 \mathrm{C}$ & $2,53 \mathrm{~A}$ & $0,35 \mathrm{~B}$ \\
150 & $4,39 \mathrm{~B}$ & $2,40 \mathrm{~A}$ & $0,39 \mathrm{AB}$ \\
300 & $5,19 \mathrm{AB}$ & $2,80 \mathrm{~A}$ & $0,41 \mathrm{~A}$ \\
450 & $5,23 \mathrm{~A}$ & $2,80 \mathrm{~A}$ & $0,39 \mathrm{AB}$ \\
\hline Médias & 4,37 & 2,63 & 0,39 \\
Teste F & $7,25^{*}$ & $0,19^{\text {ns }}$ & $0,002^{*}$ \\
CV & 9,87 & 9,32 & 6,72 \\
\hline
\end{tabular}

As médias seguidas de mesma letra não diferem estatisticamente entre si pelo Teste de Tukey a 5\% de probabilidade. * Significativo a $5 \%$ de probabilidade; ${ }^{n s}$ Não significativo $(p>0,05)$ uso do recipiente de maior capacidade volumétrica (vaso pequeno $\left.-450 \mathrm{~cm}^{3}\right)$. Os menores valores foram obtidos com o tratamento: copo pequeno $\left(50 \mathrm{~cm}^{3}\right)$ para a $\mathrm{AM}, \mathrm{NF}$, DP, MFPA e MSPA.

De acordo com os resultados observados, verifica-se que quanto maior o volume do recipiente, maior o desenvolvimento da muda, graças ao maior volume de substrato, maior quantidade de água e de nutrientes, maior espaço para a expansão do sistema radicular e, consequentemente, aumento na absorção de nutrientes.

Barros (1997), ao estudar diferentes recipientes, na produção de mudas de Eucaliptus grandis, concluiu que quanto maior o volume do recipiente empregado, maior foi a massa total da muda, massa da matéria seca da parte aérea e, também, maior área foliar das plântulas.

Os resultados obtidos estão de acordo com os de vários autores, como: Malavasi \& Malavasi, (2003); Paulino et al., (2003); Freitas et al., (2005); Bomfim, (2006); e Rocha, (2007). Em todos esses trabalhos, os autores verificaram que recipientes de menor volume ocasionam diminuição no desenvolvimento das mudas em viveiro e de plantas no campo, nas seguintes culturas: Cordia trichotoma e Jacaranda micranta; acácia negra; eucalipto; abacaxizeiro e helicônia, por causa da redução do sistema radicular das mudas analisadas pelos autores.

Segundo Gonzáles (1988), existe certa contradição quanto à utilização de recipientes grandes e pequenos. Os recipientes grandes, apesar de proporcionarem um melhor desenvolvimento das mudas, acabam gerando, por suas dimensões, maiores custos de produção, de transporte, de distribuição e de plantio. Por outro lado, os recipientes pequenos, mesmo podendo limitar, de alguma maneira, o desenvolvimento das plantas, acarretam custos relativamente menores. No entanto, deve-se planejar o plantio de acordo com o mercado e com as condições do produtor; portanto a utilização do recipiente maior só é vantajosa quando o custo não for um fator limitante.

Tabela 2. Valores médios das variáveis: altura da muda (AM), número de folhas (NF), diâmetro do pseudocaule (DP), massa fresca da parte aérea (MFPA), massa fresca do sistema radicular (MFSR), massa seca da parte aérea (MSPA) e massa seca do sistema radicular (MSSR) das mudas de bastão do imperador em função do volume dos recipientes, aos 50 DAT, Embrapa Agroindústria Tropical, Fortaleza, Ceará, 2009

\begin{tabular}{lccccccc}
\hline $\begin{array}{c}\text { Vol. dos Recipientes } \\
\left(\mathbf{c m}^{3}\right)\end{array}$ & $\begin{array}{c}\text { AM } \\
(\mathbf{c m})\end{array}$ & $\mathbf{N F}$ & $\begin{array}{c}\text { DP } \\
(\mathbf{c m})\end{array}$ & $\begin{array}{c}\text { MFPA } \\
(\mathbf{g})\end{array}$ & $\begin{array}{c}\text { MFSR } \\
(\mathbf{g})\end{array}$ & $\begin{array}{c}\text { MSPA } \\
(\mathbf{g})\end{array}$ & $\begin{array}{c}\text { MSSR } \\
(\mathbf{g})\end{array}$ \\
\hline 50 & $4,29 \mathrm{C}$ & $2,41 \mathrm{C}$ & $0,36 \mathrm{C}$ & $1,17 \mathrm{C}$ & $0,19 \mathrm{~B}$ & $0,08 \mathrm{C}$ & $0,08 \mathrm{~A}$ \\
150 & $6,44 \mathrm{~B}$ & $3,23 \mathrm{BC}$ & $0,46 \mathrm{~B}$ & $2,33 \mathrm{~B}$ & $0,19 \mathrm{~B}$ & $0,19 \mathrm{~B}$ & $0,09 \mathrm{~A}$ \\
300 & $6,50 \mathrm{~B}$ & $3,47 \mathrm{AB}$ & $0,50 \mathrm{~B}$ & $2,56 \mathrm{~B}$ & $0,20 \mathrm{~B}$ & $0,20 \mathrm{~B}$ & $0,09 \mathrm{~A}$ \\
450 & $9,45 \mathrm{~A}$ & $4,33 \mathrm{~A}$ & $0,61 \mathrm{~A}$ & $7,14 \mathrm{~A}$ & $0,49 \mathrm{~A}$ & $0,49 \mathrm{~A}$ & $0,13 \mathrm{~A}$ \\
\hline Média & 6,67 & 3,36 & 0,48 & 3,30 & 0,21 & 0,24 & 0,10 \\
Teste & $22,45^{*}$ & $3,14^{*}$ & $0,01^{*}$ & $34,61^{*}$ & $6,53^{*}$ & $0,15^{*}$ & $0,002^{\text {ns }}$ \\
FCV & 8,84 & 14,08 & 8,40 & 12,76 & 18,05 & 21,38 & 26,90 \\
\hline
\end{tabular}

*As médias seguidas de mesma letra minúscula não diferem estatisticamente entre si, pelo Teste de Tukey a 5\% de probabilidade.

* Significativo a $5 \%$ de probabilidade; ${ }^{n s}$ Não significativo $(p>0,05)$ 


\section{CONCLUSÕES}

O vaso de capacidade volumétrica de $450 \mathrm{~cm}^{3}$ é o recipiente mais adequado para aclimatização de bastão do imperador, pois proporcionou melhor desenvolvimento das mudas.

\section{REFERÊNCIAS}

Barros SBM (1997) Avaliação de recipientes na produção de mudas de tomate (Lycopersicon esculentum Mill.) e pepino (Cucumis melo L.). Dissertação de Mestrado. Universidade de São Paulo, Piracicaba. 70p.

Bezerra FC \& Loges V (2005) Zingiberaceae. In: Terao D, Carvalho ACPP \& Barroso TCSF (Eds.) Flores tropicais. Brasilia, Embrapa Informações Tecnologicas. 225p.

Bomfim GV (2006) Efeitos de lâminas e freqüências de irrigação e de tipos e volumes de substrato na aclimatização de mudas micropropagadas de abacaxizeiro ornamental. Dissertação de Mestrado. Universidade Federal do Ceará, Fortaleza. 167p.

Brainerd KE \& Fuchigami LH (1981) Acclimatization of aseptically cultured plants to low relatively humidity. Journal of the American Society of Horticultural Science, 106:515518 .

Freitas AS, Barroso DG, Carneiro JGA, Penchel RM, Lamônica KR \& Ferreira DA (2005) Desempenho radicular de mudas de eucalipto produzidas em diferentes recipientes e substratos. Revista Árvore, 29:853-861.

Gonzáles RA (1988) Estudio sobre el comportamiento en viveiro de Pinus caribaea var. caribaea cultivado en envases de polietileno de 12 dimensiones diferentes. Revista Forestal Baracoa, 18:39-51.

Kämpf AN (2000) Produção comercial de plantas ornamentais. Guaiba, Agropecuária. 254p.

Loges V, Teixeira MCF, Castro ACR \& Costa AS (2005) Colheita, pós-colheita e embalagem de flores tropicais em Pernambuco. Horticultura Brasileira, 23:699-702.

Malavasi UC \& Malavasi MM (2003) Efeito do tubete no crescimento inicial de Cordia trichotoma (Vell.) Arrab ex steud e Jacaranda micranta Cham. Revista Ciências Exatas e Naturais, 5:211-218.

Paulino AF, Medina CC, Neves CSVJ, Azevedo MCB, Higa AR \& Simon A (2003) Distribuição do sistema radicular de árvores de acácia negra oriundas de mudas produzidas em diferentes recipientes. Revista Árvore, 27:605-610.

Rocha ELJ (2007) Aclimatização de mudas micropropagadas de helicônia sob diferentes lâminas de irrigação, tipos e volumes de substrato. Dissertação de Mestrado. Universidade Federal do Ceará, Fortaleza. 71p.

SAEG (2005) Sistema para análises estatísticas, Versão 9.0. Viçosa, Fundação Arthur Bernardes/UFV. 